\title{
EL EJERCICIO DE LA LIBERTAD DE PENSAMIENTO, CONCIENCIA Y RELIGIÓN DEL MENOR DE EDAD EN LA ESCUELA: RESOLUCIÓN DE CONFLICTOS
}

\author{
BELÉN RODRIGO LARA \\ Profesora De Derecho Eclesiástico Del Estado \\ InSTITUTO DE ESTUdios Bursátiles (CENTRo AdSCRITo UNIVERSIDAD COMPLUTENSE DE MADRID) \\ belen.rodrigo@claustro-ieb.es
}

\begin{abstract}
SUMARIO: I. EL CONTEXTO. II. LOS PRINCIPIOS FUNDAMENTALES DE LA CONVENCIÓN SOBRE LOS DERECHOS DEL NIÑO DE 1989 EN EL ÁMBITO EDUCATIVO. III. EL DERECHO DE LIBERTAD DE PENSAMIENTO, CONCIENCIA Y RELIGIÓN. III.1. EL MENOR DE EDAD COMO SUJETO DEL DERECHO A LA LIBERTAD RELIGIOSA. ¿CUÁNDO PUEDE EJERCER EL MENOR LA LIBERTAD RELIGIOSA? III.2. LÍMITES AL EJERCICIO DEL DERECHO DE LIBERTAD RELIGIOSA Y PROTECCIÓN JURÍDICA DEL MENOR. IV. EL DERECHO A LA EDUCACIÓN Y SU RELACIÓN CON LA LIBERTAD RELIGIOSA. IV.1. EL DERECHO DE LOS PADRES A EDUCAR A SUS HIJOS CONFORME A SUS PROPIAS CONVICCIONES. IV.2. EL ESTADO COMO GARANTE DE LOS DERECHOS A LA EDUCACIÓN Y LA LIBERTAD RELIGIOSA: LOS PRINCIPIOS DE COOPERACIÓN Y NEUTRALIDAD ESTATAL EN MATERIA RELIGIOSA. V. LA DIVERSIDAD RELIGIOSA EN LA ESCUELA: LA RESPUESTA JURÍDICA ANTE DETERMINADAS SITUACIONES Y CONFLICTOS. V.1. LA SIMBOLOGÍA RELIGIOSA PERSONAL DE LOS ALUMNOS Y LAS ALUMNAS. V.2. ADAPTACIÓN DE LA DIETA POR PRESCRIPCIONES RELIGIOSAS EN LOS COMEDORES ESCOLARES. V.3. FESTIVIDADES Y CELEBRACIONES RELIGIOSAS. VI. CONCLUSIONES.
\end{abstract}

RESUMEN: La Convención sobre los Derechos del Niño de 1989 establece en el artículo 14 el derecho de libertad de pensamiento, conciencia y religión. Este trabajo tiene como doble objetivo de un lado, subrayar que los niños, niñas y adolescentes son sujetos activos del derecho de libertad de pensamiento, conciencia y religión y de otro lado, determinar cómo se manifiesta este derecho en el ámbito educativo, uno de los más importantes donde los menores se desenvuelven. La razón es la existencia en las aulas de una diversidad religiosa y cultural que proporciona situaciones enriquecedoras para la acción educativa pero que también puede generar conflictos, tensiones o dudas de cómo gestionarlo, para lo que es preciso una respuesta jurídica o recomendaciones de actuación conforme a Derecho.

Palabras Clave: derechos del niño, menores, derechos fundamentales, libertad religiosa, libertad de pensamiento, conciencia y religión, educación, diversidad, conflictos, escuela, menores.

\section{THE CHILDREN'S RIGHT TO FREEDOM OF THOUGHT, CONSCIENCE AND RELIGION AT SCHOOL}

ABSTRACT: The 1989 Convention on the Rights of the Child establishes in article 14 the right to freedom of thought, conscience and religion. This article has as a double objective on the one hand, to underline that children and adolescents are active subjects of the right to freedom of thought, conscience and religion and, on the other hand, to determine how this right manifests at the school, 
one of the most important places where children develop. The reason is the existence in the classrooms of a religious and cultural diversity that provides enriching situations for educational action but that can also generate conflicts, tensions or doubts about how to manage it, for which it is necessary a legal response or recommendations of action according to Law.

KEYWORDS: Children's rights, minors, fundamental rights, religious freedom, freedom of thought, conscience and religion, education, diversity, conflicts, school, minors.

\section{El contexto}

Los movimientos migratorios, las nuevas tecnologías y el mundo globalizado son a grandes rasgos los elementos principales que configuran unas sociedades diversas y plurales. El elemento religioso nos permite categorizar la pluralidad según la adscripción religiosa de los individuos y los colectivos. La diversidad religiosa presente en nuestra sociedad actual es una realidad a la que no es ajena el Derecho, ya que el ser o no religioso va más allá de una cuestión puramente de conciencia e interesa al Derecho en cuanto manifestación o exteriorización de la religiosidad y su incidencia en las relaciones sociales y frente a terceros (incluyendo al Estado). La cobertura jurídica a personas y colectivos la proporciona el derecho a la libertad de pensamiento, conciencia o religión, derecho fundamental recogido en los textos internacionales sobre Derechos Humanos. Además, el elemento religioso está presente en numerosas normas que regulan aspectos tan distintos como la enseñanza religiosa o el sacrificio de animales en mataderos municipales.

Podemos afirmar que las aulas escolares son el reflejo a pequeña escala de la sociedad, un microcosmos, donde observar situaciones en las que la religión y el ejercicio de la libertad religiosa se manifiestan y que no dejan de ser una representación de lo que sucede en la sociedad más global.

Sin embargo, el día a día en las aulas, hace que se presenten conflictos, tensiones o dudas derivados de la gestión del pluralismo religioso en este ámbito concreto que requieren de orientaciones jurídicas o pistas de actuación ante los mismos. Estas situaciones no siempre tienen respuestas jurídicas claras, dada la complejidad de algunos casos o la escasa o nula regulación al respecto, por lo que se requiere una interpretación sobre el caso concreto. Este análisis deberá hacerse tomando como referente el contexto, los sujetos intervinientes y una ponderación de los derechos en juego. Los elementos de partida sobre los que debemos centrarnos son seis: el lugar: la escuela, el derecho a la educación, el derecho de los padres a elegir la educación de sus hijos, el derecho a la libertad de pensamiento, conciencia y religión, derecho a la identidad y la nacionalidad y la cuestión de las minorías.

La relación entre todos estos componentes la centramos en el lugar donde se producen: la escuela. Las aulas son el sitio donde los niños, niñas y adolescentes invierten gran parte de su tiempo y donde son formados y educados, educación que reciben de la acción de los profesores y del resto de la comunidad educativa. El ámbito donde se desenvuelve el menor es primordial, dado que allí también recibe información, influencias $\mathrm{y}$ se forma en valores y habilidades sociales. No obstante, el principal transmisor y responsable de la educación de los hijos son los padres o tutores de los menores de edad, 
considerándose por el derecho civil como una función esencial de la patria potestad o la tutela1. Este va a ser otro elemento primordial que confluye en la cuestión de la diversidad religiosa en las aulas; derivado del derecho a la educación y la patria potestad, los padres tendrán el derecho a educar a sus hijos conforme a sus propias convicciones ${ }^{2}$, siendo el ejemplo de esta manifestación el derecho a elegir centro educativo y la enseñanza religiosa 3 . A este elemento se suma el papel desempeñado por la escuela pública ante el derecho de libertad religiosa tanto de los padres como de los propios alumnos y alumnas, y es que el Estado, a través de los centros educativos de titularidad pública, deben regirse por el principio de neutralidad en materia religiosa. La neutralidad se predica del Estado, no de la sociedad civil, ni por tanto de la escuela. La escuela pública es plural, abierta y un espacio en el que confluyen distintas ideologías y creencias. La neutralidad estatal en la escuela debe entenderse como garante del derecho de libertad religiosa y la pluralidad con el límite en sus acciones de no adoctrinar a los alumnos ${ }^{4}$.

Finalmente, los otros elementos a añadir para configurar el contexto donde van a surgir las situaciones y conflictos en la escuela por motivos religiosos, es el derecho a la

\footnotetext{
1 Artículo 154 del Código Civil español.

2 OLMOS ORTEGA, Ma E., «El derecho de los padres a decidir la formación religiosa y moral de sus hijos», en Cano Ruiz, I. (ed.), La enseñanza de la religión en la escuela pública, Comares, Granada, 2014.
}

${ }^{3}$ Los textos internaciones recoge el derecho de los padres en el artículo 26 de la Declaración Universal de Derechos Humanos (DUDH), de 10 de diciembre de 1948 afirmando que «[l]os padres tendrán derecho preferente a escoger el tipo de educación que habrá de darse a sus hijos». El documento internacional específico en el ámbito educativo, la Declaración de la UNESCO sobre la lucha contra la discriminación en el ámbito de la enseñanza de 14 de diciembre de 1960 declara en el artículo 5 que «[l]os Estados Partes en la presente Convención convienen: [...]b. En que debe respetarse la libertad de los padres o, en su caso, de los tutores legales, [...]2. de dar a sus hijos, según las modalidades de aplicación que determine la legislación de cada Estado, la educación religiosa y moral conforme a sus propias convicciones; en que, además, no debe obligarse a ningún individuo o grupo a recibir una instrucción religiosa incompatible con sus convicciones». El artículo 13.3 del Pacto Internacional de Derechos Económicos, Sociales y Culturales (PISDEC), de 19 de diciembre de 1966 expresa que «[l]os Estados Partes en el presente Pacto se comprometen a respetar la libertad de los padres y, en su caso, de los tutores legales, de escoger para sus hijos o pupilos escuelas distintas de las creadas por las autoridades públicas, siempre que aquéllas satisfagan las normas mínimas que el Estado prescriba o apruebe en materia de enseñanza, y de hacer que sus hijos o pupilos reciban la educación religiosa o moral que esté de acuerdo con sus propias convicciones». En cuanto al ámbito regional europeo, destacamos el artículo 2 del Protocolo Adicional al Convenio Europeo de Derechos Humanos (PA del CEDH) que afirma «[el] Estado, en el ejercicio de las funciones que asuma en el campo de la educación y de la enseñanza, respetará el derecho de los padres a asegurar esta educación y esta enseñanza conforme a sus convicciones religiosas y filosóficas». El art. 14.3 de la Carta Europea de Derechos Fundamentales de la Unión Europea de 2000 declara que «[s]e respetan, de acuerdo con las leyes nacionales que regulen su ejercicio, la libertad de creación de centros docentes dentro del respeto a los principios democráticos, así como el derecho de los padres a garantizar la educación y la enseñanza de sus hijos conforme a sus convicciones religiosas, filosóficas y pedagógicas». En el ordenamiento jurídico el derecho de los padres aparece en el elenco de derechos fundamentales recogidos por la Constitución de 1978, en relación con el derecho a la educación y la libertad de enseñanza, en el artículo 27.3: «Los poderes públicos garantizan el derecho que asiste a los padres para que sus hijos reciban la formación religiosa y moral que esté de acuerdo con sus propias convicciones».

${ }^{4}$ MARTÍNEZ-TORRÓN, J., «Universalidad, diversidad y neutralidad en la protección de la libertad religiosa en la jurisprudencia del Tribunal Europeo de Derechos Humanos», en Martínez-Torrón, J., Meseguer Velasco, S. y Palomino Lozano, R. (coords.), Religión, Matrimonio y Derecho ante el siglo XXI. Estudios en Homenaje al Prof. Navarro-Valls, Iustel, Madrid, 2013; OTADUY, J., «Neutralidad ideológica del Estado y del sistema educativo público», en Jornada de Estudio sobre «Educación para la Ciudadanía», Conferencia Episcopal Española, 2006, ROCA, M. J., «Deberes de los poderes públicos para garantizar el respeto al pluralismo cultural, ideológico y religioso en el ámbito escolar», en Revista General de Derecho Canónico y Derecho Eclesiástico del Estado 17 (2008). 
identidad y la nacionalidad de los sujetos intervinientes, que se forja entre otros con los componentes religioso y cultural. El apunte último a este contexto es la consideración de minorías (religiosas, de procedencia geográfica...) en muchas ocasiones de las personas intervinientes en estas situaciones y/o conflictos en la escuela, factor importante al objeto de proteger sus derechos como minorías y no se vean menoscabados por el resto.

En definitiva, los cambios sociales, la diversidad también presente en las aulas, hace que tengamos que afrontar situaciones, también conflictivas, desconocidas hasta ahora que nos invitan a conocer y tratar nuevas realidades. El sociólogo francés Alain Touraine describe que «como vivimos en sociedades de cambio, mezcla y también desocialización y aislamiento, tenemos que fortalecer en cada uno la capacidad de vivir activamente el cambio. Si recurrimos únicamente a principios de orden, no haremos sino aumentar la distancia social entre quienes pertenecen a las categorías centrales y quienes viven en zonas periféricas, dominadas por la inseguridad y la dependencia» ${ }^{5}$. Y en relación a la escuela afirma que «[...] exige una escuela social y culturalmente heterogénea, que se aleje lo más posible de la escuela comunitaria definida por la pertenencia de todos al mismo conjunto social, cultural o nacional» 6 .

\section{Los principios fundamentales de la Convención sobre los Derechos del Niño de 1989 en el ámbito educativo: especial referencia al interés superior del niño}

Desde 1989 la comunidad internacional dispone de un texto jurídico vinculante para los Estados firmantes que recoge los derechos de los menores de edad y los mecanismos para su protección y difusión. Los cuatro principios fundamentales de la Convención sobre los Derechos del Niño (en adelante CDN) son: La no discriminación (art. 2), el interés superior del niño (art. 3), el derecho a la vida, la supervivencia y el desarrollo (art. 6) y los derechos de participación y a ser escuchado (art. 12). Cada uno de estos principios son susceptibles y merecedores de estudios particulares y profundos, por lo que la breve reseña que hacemos en este trabajo es al objeto de remarcar la importancia de atenderlos en todo lo referente a las situaciones en las que participen menores de edad, como es el caso que estamos tratando: situaciones y conflictos en la escuela con elemento religioso. En este sentido, podemos establecer la relación entre derecho a la libertad religiosa con cada uno de estos principios fundamentales.

En cuanto al primer principio mencionado es evidente la conexión entre la adscripción religiosa de los menores y el no ser discriminados por este motivo ${ }^{7}$. Aplicándolo

\footnotetext{
5 TOURAINE, A., ¿Podremos vivir juntos?, 1997, p. 279.

6 TOURAINE, A., Ibidem, p. 278.

7 Art. 2 CDN: «1. Los Estados Partes respetarán los derechos enunciados en la presente Convención y asegurarán su aplicación a cada niño sujeto a su jurisdicción, sin distinción alguna, independientemente de la raza, el color, el sexo, el idioma, la religión, la opinión política o de otra índole, el origen nacional, étnico o social, la posición económica, los impedimentos físicos, el nacimiento o cualquier otra condición del niño, de sus padres o de sus representantes legales. 2. Los Estados Partes tomarán todas las medidas apropiadas para garantizar que el niño se vea protegido contra toda forma de discriminación o castigo por causa de la condición, las actividades, las opiniones expresadas o las creencias de sus padres, o sus tutores o de sus familiares».
}

Además de la referencia al art. 2 de la CDN, la no discriminación por motivos religiosos entre otros se encuentra regulada en el art. 14 de la Constitución Española de 1978 «Los españoles son iguales ante la ley, sin 
en el contexto escolar, ningún menor debe sufrir discriminación por razón de su adscripción religiosa o por no profesar ninguna. Este principio fundamental de la CDN de no discriminación también constituye principio informador del Derecho Eclesiástico en la medida en que el Estado y, por tanto, los centros educativos públicos, no pueden tratar de diferente forma injustificadamente a las personas y colectivos por razón de sus creencias.

Por otra parte, el derecho a la vida es uno de los derechos más básicos de toda persona. La existencia física supone la virtualidad per se de ser sujeto de derechos y, por tanto, es un presupuesto para que se puedan disfrutar de todos los derechos. Esta afirmación que podría tildarse de perogrullada es muy importante en aras de la protección $\mathrm{y}$ el fomento de que todos los niños y niñas tengan unas condiciones de vida dignas y saludables que les procuren un desarrollo tanto físico como psicológico adecuado, la base para que puedan ejercer sus derechos. Consecuencia de esto, los derechos de participación y a ser escuchado constituye una consecuencia lógica para procurar el desarrollo intelectual y social de los menores, lo que en los textos jurídicos aparece como el derecho al libre desarrollo de la personalidad. Este elemento es fundamental ya que la persona constituye un todo en lo físico más lo espiritual, no basta con la existencia física sino que la conciencia, la espiritualidad y, en definitiva, la capacidad para obrar y desenvolverse en la vida conforme a sus principios y valores constituyen el eje fundamental de la dignidad humana. Esto se materializa en que los derechos a la vida y de libertad de pensamiento, conciencia y religión constituyen las dos caras de la moneda en la podemos identificar la esencia humana: vida física-vida espiritual o conciencia. Todo ello es aplicable a los menores de edad, en cuanto sujeto de derechos por el mero hecho de ser personas, independientemente de su capacidad de obrar para determinados actos regulados por los distintos ordenamientos jurídicos.

Por otro lado, los derechos de participación y a ser escuchados de los menores suponen que éstos tendrán que ser tomados en cuenta en la medida de su capacidad y desarrollo evolutivo y dependiendo de los casos de que se trate. Ejemplo de ello en el ámbito civil es lo relativo a los procesos de adopción en el que el menor tendrá que ser escuchado siempre si es mayor de 12 años, así como en todos los procesos familiares. Con referencia al ámbito escolar, un claro ejemplo de derechos de participación es el proceso de representación de alumnos (delegado de clase) y Consejo Escolar del centro.

Finalmente, y como principio vertebrador del resto y más conocido en lo que atañe a los menores de edad, hay que mencionar el interés superior del niño. Esta expresión, que recoge prácticamente cualquier normativa relacionada con menores, es difícil de precisar desde un punto de vista general, precisamente porque así es como debe ser para atender a su finalidad: el caso concreto. No obstante, cuando la doctrina jurídica y en artículos de divulgación no necesariamente jurídicos, se refieren a este principio lo definen con la recurrente y manida expresión, aunque cierta desde el punto de vista general, de ser un «concepto jurídico indeterminado». Precisamente, de su imprecisión jurídica deriva la ventaja de aplicarlo con mayor grado de justicia a cada caso concreto. Aunque, ciertamente, esta ventaja provoca dificultades en los agentes encargados de aplicarlo, reclamando

que pueda prevalecer discriminación alguna por razón de nacimiento, raza, sexo, religión, opinión o cualquier otra condición o circunstancia personal o social». 
criterios interpretativos homogéneos para su aplicación y efectividad. En este sentido, además de la doctrina que ha estudiado con detalle este principio ${ }^{8}$, el Comité de Derechos del Niño realizó la Observación General no 14 (2013) sobre el derecho del niño a que su interés superior sea una consideración primordial (Aprobada por el Comité en su $62^{\circ}$ período de sesiones (14 de enero a 1 de febrero de 2013). Este documento viene a establecer las líneas interpretativas a las que hacíamos antes referencia, para poder aplicarlo en todas las decisiones que afecten a los menores. Esta Observación del Comité de los Derechos del Niño ha inspirado reformas legislativas para aclarar este concepto, como en la Ley Orgánica 1/1996, de 15 de enero, de Protección Jurídica del Menor, reformada en 2015 9.

De acuerdo con la definición que establece el art. 3 de la CDN y la Observación no 14 del Comité de Derechos del Niño, podemos definir el interés del menor en una triple vertiente: como derecho sustantivo que puede invocarse ante los procedimientos y directamente aplicable; como un principio jurídico interpretativo, esto significa que si una norma admite varias interpretaciones habrá que optar por la que más beneficie al menor; $y$ en último lugar, como una norma de procedimiento. Esto significa que cualquier medida que se tome respecto de un niño o un grupo de niños deberá ser suficientemente ponderada y justificada, analizando todos los efectos (positivos y negativos) que marcan la decisión.

La aplicación del interés superior del niño, en palabras expresadas por el Comité de Derechos del Niño en la Observación General no 14 del Comité de Derechos del Niño, «exige adoptar un enfoque basado en los derechos, en el que colaboren todos los intervinientes, a fin de garantizar la integridad física, psicológica, moral y espiritual holísticas del niño y promover su dignidad humana». Este «enfoque basado en los derechos» implica que la determinación del interés del menor por un adulto según su parecer no puede primar sobre la obligación de respetar todos los derechos del niño enunciados en la Convención.

Como hemos expresado en líneas precedentes, acomodar esta teoría a cada caso concreto es lo realmente complicado y a lo que la Observación no 14 del Comité de Derechos del Niño y su traslado al art. 2 de la Ley Orgánica de Protección Jurídica del Menor española han tratado de poner las bases para hallar una adecuada interpretación. El párrafo 2 del art. 2 de la LOPJM establece unos criterios generales para determinar el interés superior del menor, los cuales son: «a) La protección del derecho a la vida, supervivencia y desarrollo del menor y la satisfacción de sus necesidades básicas, tanto materiales, físicas y educativas como emocionales y afectivas. b) La consideración de los deseos, sentimientos y opiniones del menor, así como su derecho a participar progresivamente, en función de su edad, madurez, desarrollo y evolución personal, en el proceso de determinación de su interés superior. c) La conveniencia de que su vida y desarrollo tenga lugar en un entorno familiar adecuado y libre de violencia. Se priorizará la permanencia en su familia de origen y se preservará el mantenimiento de sus relaciones familiares [...] d) La preservación de la identidad, cultura, religión, convicciones, orientación e identidad sexual o idioma del menor,

\footnotetext{
8 MARTÍNEZ GARCÍA, C., DEL MORAL BLASCO, C., Guía para la evaluación y determinación del interés superior del niño, Cátedra Santander de Derecho y Menores, 2017. https://repositorio.comillas.edu/xmlui/handle/11531/26167

9 Ley Orgánica 8/2015, de 22 de julio, de modificación del sistema de protección a la infancia y a la adolescencia y Ley 26/2015, de 28 de julio, de modificación del sistema de protección a la infancia y a la adolescencia.
} 
así como la no discriminación del mismo por éstas o cualesquiera otras condiciones, incluida la discapacidad, garantizando el desarrollo armónico de su personalidad».

Es destacable como criterio general para determinar el interés del menor la preservación de la identidad, cultura y religión del menor y no ser discriminado por ello, así como la consideración de sus opiniones y el derecho a su participación en las decisiones que le afecten. Esto va a ser primordial para resolver conflictos en la escuela basados en el derecho de libertad religiosa de los alumnos y sus familias.

Sigue la ley afirmando que estos criterios se ponderarán teniendo en cuenta los siguientes elementos generales: a) La edad y madurez del menor. b) La necesidad de garantizar su igualdad y no discriminación por su especial vulnerabilidad, ya sea por la carencia de entorno familiar, sufrir maltrato, su discapacidad, su orientación e identidad sexual, su condición de refugiado, solicitante de asilo o protección subsidiaria, su pertenencia a una minoría étnica, o cualquier otra característica o circunstancia relevante. c) El irreversible efecto del transcurso del tiempo en su desarrollo. d) La necesidad de estabilidad de las soluciones que se adopten para promover la efectiva integración y desarrollo del menor en la sociedad, así como de minimizar los riesgos que cualquier cambio de situación material o emocional pueda ocasionar en su personalidad y desarrollo futuro. e) La preparación del tránsito a la edad adulta e independiente, de acuerdo con sus capacidades y circunstancias personales.

Los anteriores elementos deberán ser valorados conjuntamente, conforme a los principios de necesidad y proporcionalidad, de forma que la medida que se adopte en el interés superior del menor no restrinja o limite más derechos que los que ampara.

Además, también se prevé que «en caso de concurrir cualquier otro interés legítimo junto al interés superior del menor deberán priorizarse las medidas que, respondiendo a este interés, respeten también los otros intereses legítimos presentes. En caso de que no puedan respetarse todos los intereses legítimos concurrentes, deberá primar el interés superior del menor sobre cualquier otro interés legítimo que pudiera concurrir. Las decisiones y medidas adoptadas en interés superior del menor deberán valorar en todo caso los derechos fundamentales de otras personas que pudieran verse afectados».

En conclusión, tanto la Observación General no 14 del Comité de Derechos del Niño como la ley española de protección jurídica del menor, en su reforma del año 2015, sistematizan como elementos para determinar el interés superior del niño: 1. La opinión del niño. Escuchar al menor mostrando su postura sobre el conflicto. 2. La identidad del niño. Como elemento de su identidad encontramos su religión y creencias, nacionalidad... 3. La preservación del entorno familiar y mantenimiento de las relaciones, en los casos en los que se presenten situaciones que puedan dar lugar a separación del hijo de sus padres. 4. El cuidado, la protección y la seguridad del niño, entendiendo dentro de estos conceptos el cuidado «emocional». 5. La situación de vulnerabilidad, por ejemplo, niños pertenecientes a minorías, con capacidades limitadas... 6. El derecho del niño a la salud y 7. El derecho a la educación.

Una de las consideraciones que podemos deducir de lo expresado es que la determinación del interés del menor se lleva a cabo con muchos elementos en juego y con 
la intervención de varias personas. Así, apoyándonos en los textos legales, en primer lugar, son los padres o tutores del menor, apareciendo la figura del Estado como garante y protector de los derechos de los menores en el caso de que éstos sean vulnerados en el ámbito familiar o haya conflicto entre los padres. A estos hay que añadir al propio menor en el ejercicio de su derecho a ser escuchado y a participar en los asuntos que le afecten, de acuerdo con su grado de madurez. Menor al que se suele tener al margen, a veces por razones obvias, como la edad del niño, pero otras veces completamente olvidado a pesar de tener edad suficiente para darle voz en los asuntos que le afectan. Esto significa que el menor, con base en el derecho a ser escuchado en los procedimientos que le afecten, podrá ser partícipe en la determinación de su mejor interés ${ }^{10}$.

En definitiva, los cuatro principios fundamentales de la CDN están relacionados entre sí, asemejándose a las piezas de un puzle que encajadas constituyen el marco sobre el que se sustentan los derechos de la infancia y que son necesarios tener como punto de partida a la hora de enfocar el tratamiento de las situaciones y conflictos en la escuela con componente religioso.

\section{El derecho de libertad de pensamiento, conciencia y religión}

III.1. El menor de edad como sujeto del derecho a la libertad religiosa. ¿Cuándo puede ejercer el menor la libertad religiosa?

La libertad religiosa se configura como un derecho fundamental referido a la dimensión espiritual y transcendente del ser humano. Podemos afirmar que este derecho constituye junto con el derecho a la vida las dos esferas principales del ser humano: la física y la espiritual. Así lo hemos señalado con anterioridad al referirnos a los principios fundamentales de la CDN. Esto significa que el derecho a la vida constituiría el estado físico elemental y necesario para ser sujeto del resto de derechos humanos y el derecho a la libertad religiosa supondría la parte no física, la relativa a la conciencia y al libre pensamiento.

El derecho a la libertad de pensamiento, de conciencia y de religión está recogido en los textos internacionales sobre derechos humanos y en los Convenios europeos ratificados por España ${ }^{11}$. Estos documentos se refieren a ella como un derecho individual y colectivo

10 SÁNCHEZ HERNÁNDEZ, C., «Capacidad natural e interés del menor maduro como fundamento del libre ejercicio de los derechos de la personalidad», en Estudios jurídicos en homenaje al profesor Luis DíezPicazo, 1aㅡ ed., vol. 4, Civitas, Madrid, 2003, pp.952 a 974.

11 Artículo 18 Declaración Universal de los Derechos del Hombre, de 10 de diciembre de 1948 (DUDH), artículo 18 Pacto Internacional de Derechos Civiles y Políticos (PIDCP), firmado el 19 de diciembre de 1966, artículo 13.3 del Pacto Internacional de Derechos Económicos, Sociales y Culturales (PISDEC), de 19 de diciembre de 1966, Comité de Derechos Humanos de Naciones Unidas plasmada en la Observación General número 22, sobre la libertad de pensamiento, de conciencia y de religión, art.2 Declaración sobre la eliminación de todas las formas de intolerancia y discriminación fundadas en la religión o las convicciones, aprobada el 25 de noviembre de 1981, art. 9 Convenio para la Protección de los Derechos Humanos y de las Libertades Fundamentales (CEDH), firmado por los Estados miembros del Consejo de Europa, el 4 de noviembre de 1950, artículo 2 del Protocolo Adicional al Convenio Europeo de Derechos Humanos (PA del CEDH), art. 10 Carta de los Derechos Fundamentales de la Unión Europea, firmada el 7 de diciembre de 2000, reconoce la libertad de pensamiento, de conciencia y de religión. 
cuyo ejercicio o manifestación externa debe considerarse de un modo amplio, comprendiendo en el mismo el realizar actos de culto, la enseñanza, la práctica y el cumplimiento de sus prescripciones religiosas.

No obstante, como cualquier derecho, incluidos los derechos fundamentales, no son ilimitados 12 , sino que están sujetos a unas restricciones a su ejercicio, que en cualquier caso son establecidas por la ley y su aplicación deberán ser las necesarias, sin interpretaciones amplias, en una sociedad democrática para proteger la seguridad, el orden, la salud o moral pública y los derechos y libertades fundamentales de los demás.

En el ordenamiento jurídico español, la libertad religiosa se regula en el artículo 16 de la Constitución de 1978, dentro de los derechos fundamentales y libertades públicas estableciendo que «1. Se garantiza la libertad ideológica, religiosa y de culto de los individuos y las comunidades sin más limitación, en sus manifestaciones, que la necesaria para el mantenimiento del orden público protegido por la ley. 2. Nadie podrá ser obligado a declarar sobre su ideología, religión o creencias. 3. Ninguna confesión tendrá carácter estatal. Los poderes públicos tendrán en cuenta las creencias religiosas de la sociedad española y mantendrán las consiguientes relaciones de cooperación con la Iglesia Católica y las demás confesiones».

El Derecho observará el factor religioso como elemento presente en la sociedad y en sus distintas manifestaciones por parte de los sujetos y/o colectividades, por lo que el objeto del Derecho es no tanto si una persona tiene una u otra religión o si no profesa ninguna, como el ejercicio de este derecho en el ámbito social.

Respecto de esta cuestión, el Tribunal Constitucional español en diversas sentencias ${ }^{13}$ se ha referido a la doble dimensión del derecho de libertad religiosa. Por un lado, la dimensión interna que «garantiza la existencia de un claustro íntimo de creencias y, por tanto, un espacio de autodeterminación intelectual ante el fenómeno religioso, vinculado a la propia personalidad y dignidad individual» y por otro, la dimensión externa de «agere licere» que permite a las personas actuar de acuerdo con sus propias convicciones y mantenerlas frente a terceros. Además, con la plena inmunidad de coacción del Estado o de cualesquiera grupos sociales.

La normativa específica en España sobre libertad religiosa se desarrolla, además de en la Constitución de 1978, en la Ley Orgánica 7/1980, de Libertad Religiosa, de 5 de julio (en adelante LOLR).

En el ámbito específico de la infancia, la CDN de 1989 en el artículo 14 se refiere a este derecho en los siguientes términos: «1. Los Estados Partes respetarán el derecho del niño a la libertad de pensamiento, de conciencia y de religión. 2. Los Estados Partes respetarán los derechos y deberes de los padres y, en su caso, de los representantes legales, de guiar al niño en el ejercicio de su derecho de modo conforme a la evolución de sus facultades. 3. La libertad de profesar la propia religión o las propias creencias estará sujeta

\footnotetext{
12 MARTÍNEZ-TORRÓN, J. «La protección internacional de la libertad religiosa», en Tratado de Derecho Eclesiástico, Eunsa, Pamplona, 1994, pp. 223-224; COMBALÍA SOLIS, Z. «Los límites del derecho de libertad religiosa», Tratado de Derecho Eclesiástico, Eunsa, Pamplona, 1994.
}

13 SSTC 177/1996, de 11 de noviembre; 46/2001, de 15 de febrero; 19/1985, de 13 de febrero; 154/2002, de 18 de julio; 101/2004, de 2 de junio. 
únicamente a las limitaciones prescritas por la ley que sean necesarias para proteger la seguridad, el orden, la moral o la salud públicos o los derechos y libertades fundamentales de los demás».

Igualmente, el artículo 30 de la CDN hace más significativo este derecho aplicado a los menores indígenas cuando afirma que «en los Estados en que existan minorías étnicas, religiosas o lingüísticas o personas de origen indígena, no se negará a un niño que pertenezca a tales minorías o que sea indígena el derecho que le corresponde, en común con los demás miembros de su grupo, a tener su propia vida cultural, a profesar y practicar su propia religión, o a emplear su propio idioma». También es necesario referirnos al artículo 2 , relativo a la no discriminación por motivos religiosos, entre otros y al artículo 29, sobre los objetivos de la educación, el cual se refiere a que la educación deberá encaminarse a «inculcar al niño el respeto de los derechos humanos y las libertades fundamentales y de los principios consagrados en la Carta de las Naciones Unidas» y «preparar al niño para asumir una vida responsable en una sociedad libre, con espíritu de comprensión, paz, tolerancia, igualdad de los sexos y amistad entre todos los pueblos, grupos étnicos, nacionales y religiosos y personas de origen indígena».

En el ámbito regional europeo citar la Carta Europea de los Derechos del Niño de 1992, que se refiere a la libertad religiosa del menor en los principios 18 «Todo niño tiene derecho a la libertad de conciencia, de pensamiento y de religión...» y 19: «Todo niño tiene derecho a gozar de su propia cultura, a practicar su propia religión...».

La regulación jurídica específica sobre menores en España también recoge el derecho de libertad religiosa en la Ley Orgánica 1/1996, de 15 de enero, de Protección Jurídica del Menor ${ }^{14}$, en el artículo 6 se refiere a que «1. El menor tiene derecho a la libertad de ideología, conciencia y religión. 2 . El ejercicio de los derechos dimanantes de esta libertad tiene únicamente las limitaciones prescritas por la Ley y el respeto de los derechos y libertades fundamentales de los demás. 3. Los padres o tutores tienen el derecho y el deber de cooperar para que el menor ejerza esta libertad de modo que contribuya a su desarrollo integral».

Una vez establecido el marco normativo, la dificultad surge en la práctica cuando nos preguntamos si los menores tienen la suficiente capacidad para poder ejercer su derecho de libertad religiosa. Algunos ordenamientos jurídicos establecen una edad a partir de la cual el menor es capaz para ejercer este derecho plenamente ${ }^{15}$. Otros ordenamientos jurídicos, como el español responden con que se debe atender a la madurez del menor. Las leyes no definen el concepto de la madurez o suficiente juicio a efectos de determinar la capacidad de un menor para ejercer su derecho de libertad religiosa, optando así por la utilización de un concepto impreciso desde un punto de vista jurídico, que aunque representa un alto grado de inseguridad jurídica, permite por otro lado dar un tratamiento

\footnotetext{
14 Modificada por la Ley Orgánica 8/2015, de 22 de julio y la Ley 26/2015, de 28 de julio de modificación del sistema de protección a la infancia y a la adolescencia.

15 Caso de Portugal que fija la edad de 16 años en el art. 11.2 de la Lei da Liberdade Religiosa (Lei no 16/2001: «Os menores, a partir dos 16 anos de idade, têm o direito de realizar por si as escolhas relativas a liberdade de consciência, de religião e de culto».
} 
individualizado al cada caso concreto, atendiendo a las personas y situaciones específicas, adquiriendo así un mayor grado de atención y de equidad en las soluciones.

El concepto de «madurez o suficiente juicio» escapa a la determinación jurídica, por lo que será necesaria la orientación de las disciplinas académicas que proporcionen los datos precisos para considerar que una persona adquiere el desarrollo psíquico adecuado que le permita entender y ejercer responsablemente este derecho ${ }^{16}$. A grandes rasgos y sin ánimo de exhaustividad, dado que se trata de una disciplina ajena a nuestro conocimiento, se estima que es en la adolescencia, a partir de los 13-14 años, cuando el menor tiene suficiente capacidad intelectiva y volitiva sobre el hecho religioso, por lo que un menor de edad sería capaz de ejercer su derecho de libertad religiosa.

Las referencias a la psicología evolutiva y de desarrollo de la personalidad debe completarse con las reglas interpretativas que nos marca el Derecho. Una de estas reglas es recurrir a la analogía, regulada en el art. 4 del CC español y que procederá cuando las normas «no contemplen un supuesto específico, pero regulen otro semejante entre los que se aprecie identidad de razón».

El ordenamiento jurídico español regula supuestos en los que se establecen como más significativas las edades de 12, 14 y 16 años, coincidiendo con lo establecido por las edades de desarrollo evolutivo. Ejemplos que pueden citarse de nuestro ordenamiento jurídico son los mayores de 12 años, y antes de esa edad si se considera con suficiente juicio, que deberán ser escuchados previamente a la toma de decisiones judiciales que les afecten en los procesos de familia ${ }^{17}$. Por otra parte, a la edad de 14 años se les reconoce capacidad para otorgar testamento, salvo el ológrafo ${ }^{18}$ y testificar en juicio ${ }^{19}$. Finalmente, con 16 años los menores de edad tienen el derecho a trabajar ${ }^{20}$, aunque sujetos a unas medidas especiales de protección y contraer matrimonio si están emancipados ${ }^{21}$.

III.2. Límites al ejercicio del derecho de libertad religiosa y protección jurídica del menor

Además de aplicar los límites generales referidos, y como hemos expresado anteriormente, los menores de edad tienen una capacidad de obrar limitada. La restricción de la capacidad se fundamenta, por una parte, en que los menores aún no tienen desarrollo físico y psíquico suficiente que les permitan actuar en igualdad de condiciones con los mayores de edad en el ámbito jurídico. Esta circunstancia es suficiente para que el derecho considere al menor como persona de especial protección.

16 KOHLBERG, L., Psicología del desarrollo moral, Desclée de Brouwer, Bilbao, 1992; PIAGET, J., El criterio moral en el niño. Fontanella, Barcelona, 1971; ESQUERDA ARESTÉ, M., PIFARRÉ PAREDERO, J. Y VIÑAS SALAS, J., «El menor maduro: madurez cognitiva, psicosocial y autonomía moral», en DE LOS REYES LÓPEZ, M. y SÁNCHEZ JACOB, M. (Ed.): Bioética y Pediatría. Proyectos de vida plena, Sociedad de Pediatría de Madrid y Castilla La Mancha, Madrid, 2010, pp. 359 a 365.

${ }^{17}$ Art. 770.4 de la Ley de Enjuiciamiento Civil (LEC).

18 Arts. 663 y 688 CC.

${ }^{19}$ Art. 361 LEC.

${ }^{20}$ Art. 6 Estatuto de los Trabajadores.

${ }^{21}$ Art. 46 CC y Ley 15/2015 de 2 de Julio de Jurisdicción Voluntaria. 
Los mecanismos de protección establecidos por el Derecho son limitar la capacidad de obrar de los menores y establecer las figuras jurídicas de la patria potestad y la tutela legal, en las que los padres o tutores son titulares de unos derechos y deberes en relación con sus hijos/tutelados además de la acción del Estado como garante de los derechos del menor. Respecto a esto último, la Constitución española en su artículo 39 se refiere a que «Los poderes públicos aseguran [...] la protección integral de los hijos, iguales éstos ante la ley [...] Los niños gozarán de la protección prevista en los acuerdos internacionales que velan por sus derechos». Por otra parte, la Convención sobre los Derechos del niño recoge varios artículos en los que el papel del Estado como garante de estos derechos es fundamental. El art. 2: «Los Estados Partes respetarán los derechos enunciados en la presente Convención y asegurarán su aplicación a cada niño sujeto a su jurisdicción, sin distinción alguna [...]». El art. 4: «Los Estados Partes adoptarán todas las medidas administrativas, legislativas y de otra índole para dar efectividad a los derechos reconocidos en la presente Convención». Y el art. 5 relacionado con la funciones paternofiliales: «Los Estados Partes respetarán las responsabilidades, los derechos y los deberes de los padres o, en su caso, de los miembros de la familia ampliada o de la comunidad, según establezca la costumbre local, de los tutores u otras personas encargadas legalmente del niño de impartirle, en consonancia con la evolución de sus facultades, dirección y orientación apropiadas para que el niño ejerza los derechos reconocidos en la presente Convención».

La protección del menor es, por tanto, un elemento esencial en el Derecho de menores, y que justifica la limitación de su capacidad de obrar, sin embargo, las limitaciones a la capacidad del menor deben interpretarse de forma restrictiva, según establece el artículo 2 de la Ley Orgánica de Protección Jurídica del Menor española «[1]as limitaciones a la capacidad de obrar de los menores se interpretarán de forma restrictiva y, en todo caso, siempre en el interés superior del menor».

El límite a la capacidad de obrar del menor como forma de proteger a ésta no puede constituir un elemento que vacíe de contenido el propio derecho del menor, es decir, que «la protección del menor» no sirve como paraguas para justificar cualquier negativa al menor para ejercer sus derechos. Igualmente, esta afirmación debe interpretarse con la particularidad de que los derechos de la persona -como el derecho de libertad religiosa- no pueden ejercerse por persona distinta o en representación de su titular. De esta forma, los padres o tutores no pueden sustituir al menor ejerciendo el derecho de libertad religiosa en su nombre. En este sentido el artículo 162 del Código Civil español exceptúa de dicha representación en «los actos relativos a derechos de la personalidad u otros que el hijo, de acuerdo con las Leyes y con sus condiciones de madurez, pueda realizar por sí mismo». Esto no significa que los padres no puedan decidir sobre situaciones que afecten a sus hijos, al contrario, como titulares de la patria potestad la decisión sobre asuntos que confieren a la educación de los hijos constituye un derecho-deber, ellos son los primeros garantes de su cuidado, desarrollo y educación. No obstante, la función de los padres ha de ser la de guía o actuación en interés del hijo o tutelado no una «sustitución» del menor alegando la patria potestad, es decir, que no existe «un derecho» de los padres sobre los derechos de los hijos. En esta línea, el art. 14 de la CDN sobre el derecho de libertad religiosa del menor se refiere a que «los Estados Partes respetarán los derechos y deberes de los padres y, en su caso, de 
los representantes legales, de guiar al niño en el ejercicio de su derecho de modo conforme a la evolución de sus facultades».

La institución de la patria potestad constituye un conjunto de derechos y deberes en relación con los hijos que según recoge el artículo 154 del Código civil español «se ejercerá siempre en beneficio de los hijos, de acuerdo con su personalidad». Esto significa que en todas las situaciones en los que intervengan o se vea afectado el hijo menor de edad, se atenderá al interés superior del niño, concepto al que hemos hecho referencias en este trabajo.

\section{El derecho a la educación y su relación con la libertad religiosa}

IV.1. El derecho de los padres a educar a sus hijos conforme a sus propias convicciones

El artículo 27 de la Constitución Española ${ }^{22}$ regula la educación como un derecho fundamental estableciendo igualmente la libertad de enseñanza. El objeto de este derecho es alcanzar el pleno desarrollo de la personalidad humana en el respeto a los principios democráticos de convivencia y a los derechos y libertades fundamentales (art. 27.2 CE).

Este artículo, uno de los más extensos del texto constitucional, establece que la educación es un derecho de prestación por parte del Estado, un servicio público de carácter obligatorio y gratuito que actualmente la ley lo regula para las edades comprendidas entre los 6 y los 16 años 23 .

Por otra parte, la libertad de enseñanza es una de las manifestaciones del derecho de libertad ideológica y religiosa recogido en el artículo 16.1 y el derecho a expresar y difundir libremente los pensamientos de acuerdo con el artículo 20 de la Constitución (incluida la libertad de cátedra) y que ampara la libertad de creación de centros docentes (art. 27.6 CE) en el marco de los principios constitucionales.

Por tanto, el derecho a la educación y la libertad de enseñanza se expresa en el sistema educativo español con una pluralidad de centros educativos: centros de titularidad pública, centros de titularidad privada y centros de titularidad privada concertados con la Administración, en los que la enseñanza está subvencionada con fondos públicos. Los centros públicos se regirán por el principio de neutralidad ideológica o aconfesionalidad del Estado, aunque en sistema educativo, propiciado por diversos acuerdos con las confesiones

22 Ley Orgánica 8/1985, de 3 de julio, regula el Derecho a la Educación (LODE). Real Decreto 2377/1985, de 18 de noviembre, por el que se aprueba el Reglamento de Normas Básicas sobre Conciertos Educativos. Ley Orgánica 2/2006, de 3 de mayo, de Educación (LOE). Ley Orgánica 4/2007, de 12 de abril (LOU), por la que se modifica la Ley Orgánica 6/2001, de 21 de diciembre, de Universidades (LOU). Ley Orgánica 8/2013, de 9 de diciembre, para la Mejora de la Calidad Educativa (LOMCE), BOE núm. 310, de 27 de diciembre. De acuerdo con los artículos 148 y 149 de la CE, se establece las competencias en materia educativa a las Comunidades autónomas, por lo que habrá que atender al desarrollo normativo autonómico específico.

${ }^{23}$ Art. 4 Ley Orgánica 2/2006 de 3 de mayo, de Educación, sobre la enseñanza básica: «1. La enseñanza básica a la que se refiere el artículo 3.3 de esta Ley es obligatoria y gratuita para todas las personas. 2. La enseñanza básica comprende diez años de escolaridad y se desarrolla, de forma regular, entre los seis y los dieciséis años. No obstante, los alumnos tendrán derecho a permanecer en régimen ordinario cursando la enseñanza básica hasta los dieciocho años, cumplidos en el año en que finalice el curso, en las condiciones establecidas en la presente Ley». 
religiosas ${ }^{24}$, se puede optar por recibir enseñanza religiosa, como una expresión del derecho de los padres a educar a sus hijos conforme a sus propias convicciones, tal y como se expresa el art. 27.3 del texto constitucional español 25 .

Este derecho no solo tiene su expresión en la Constitución Española, si no que tiene un mayor abundamiento en los documentos internacionales de derechos humanos precedentes ${ }^{26}$. Al igual que en estos textos, el artículo 27.3 de la CE reconoce y garantiza «el derecho que asiste a los padres para que sus hijos reciban la formación religiosa y moral que esté de acuerdo con sus propias convicciones». Artículo al que se refiere expresamente la Ley Orgánica 8/1985, de 3 de julio reguladora del Derecho a la Educación (LODE) cuando afirma que: «Todos los centros públicos desarrollarán sus actividades con sujeción a los principios constitucionales, garantía de neutralidad ideológica y respeto de las opciones religiosas y morales a que hace referencia el artículo 27.3 de la Constitución» (Art. 18.1).

IV.2. El Estado como garante de los derechos a la educación y la libertad religiosa: Los principios de cooperación y neutralidad estatal en materia religiosa

Como hemos observado de la lectura del artículo 18.1 LODE, el derecho de los padres a educar a sus hijos debe aunarse con la neutralidad ideológico-religiosa del Estado

\footnotetext{
${ }^{24}$ Acuerdo entre el Estado Español y la Santa Sede sobre Enseñanza y Asuntos Culturales, de 3 de enero de 1979; Ley 24/1992, de 10 de noviembre, por la que se aprueba el Acuerdo de Cooperación del Estado con la Federación de Entidades Religiosas Evangélicas de España; Ley 25/1992, de 10 de noviembre, por la que se aprueba el Acuerdo de Cooperación del Estado con la Federación de Comunidades Judías de España; Ley 26/1992, de 10 de noviembre, por la que se aprueba el Acuerdo de Cooperación del Estado con la Comisión Islámica de España.

25 FERRER ORTIZ, J., «Los derechos educativos de los padres en una sociedad plural», en Revista General de Derecho Canónico y Derecho Eclesiástico del Estado 10 (2006).

${ }^{26}$ Artículo 26 de la Declaración Universal de Derechos Humanos: «Los padres tendrán derecho preferente a escoger el tipo de educación que habrá de darse a sus hijos». Artículo 18.4 del PIDCP y en el artículo 13.3 del PISDEC: «Los Estados Partes en el presente Pacto se comprometen a respetar la libertad de los padres y, en su caso, de los tutores legales, de escoger para sus hijos o pupilos escuelas distintas de las creadas por las autoridades públicas, siempre que aquéllas satisfagan las normas mínimas que el Estado prescriba o apruebe en materia de enseñanza, y de hacer que sus hijos o pupilos reciban la educación religiosa o moral que esté de acuerdo con sus propias convicciones». Artículo 5 de la Declaración de la UNESCO sobre la lucha contra la discriminación en el ámbito de la enseñanza, de 14 de diciembre de 1960 declara que: «Los Estados Partes en la presente Convención convienen: (...) b. En que debe respetarse la libertad de los padres o, en su caso, de los tutores legales, 1. de elegir para sus hijos establecimientos de enseñanza que no sean los mantenidos por los poderes públicos, pero que respeten las normas mínimas que puedan fijar o aprobar las autoridades competentes, y 2. de dar a sus hijos, según las modalidades de aplicación que determine la legislación de cada Estado, la educación religiosa y moral conforme a sus propias convicciones; en que, además, no debe obligarse a ningún individuo o grupo a recibir una instrucción religiosa incompatible con sus convicciones». El artículo 5 de la Declaración sobre la eliminación de todas las formas de intolerancia y discriminación fundadas en la religión o las convicciones: «1. Los padres o, en su caso, los tutores legales del niño tendrán el derecho de organizar la vida dentro de la familia de conformidad con su religión o sus convicciones y habida cuenta de la educación moral en que crean que debe educarse al niño. 2. Todo niño gozará del derecho a tener acceso a educación en materia de religión o convicciones conforme con los deseos de sus padres o, en su caso, sus tutores legales, y no se le obligará a instruirse en una religión o convicciones contra los deseos de sus padres o tutores legales, sirviendo de principio rector el interés superior del niño». En el marco jurídico europeo, el artículo 2 del Protocolo Adicional número 1 al Convenio Europeo de Derechos Humanos, de 20 de marzo de 1952 (PA al CEDH) afirma que: «A nadie se le puede negar el derecho a la instrucción. El Estado, en el ejercicio de las funciones que asuma en el campo de la educación y de la enseñanza, respetará el derecho de los padres a asegurar esta educación y esta enseñanza conforme a sus convicciones religiosas y filosóficas».
} 
que se materializa en lo expresado en el artículo 16.3 de la CE: «Ninguna confesión tendrá carácter estatal».

La neutralidad del Estado en materia religiosa supone que éste no debe valorar las creencias religiosas e ideológicas de los ciudadanos ni tratar de influir en la determinación de estas, tanto en el sentido de profesar como de no profesar ninguna.

El Tribunal Constitucional en varias resoluciones ha interpretado el concepto de neutralidad estatal y ha determinado que ésta garantiza la convivencia pacífica entre las distintas convicciones religiosas e ideológicas existentes en una sociedad plural y democrática (STC 340/1993, de 16 de noviembre) y también propicia el ejercicio de la libertad religiosa y de conciencia de todos los individuos, concediéndoles una esfera para la libertad de actuación con arreglo a sus propias convicciones (STC 19/1985, de 13 de febrero).

Concretando todas estas ideas en el ámbito educativo público, la neutralidad ideológico-religiosa del Estado conlleva que los centros docentes públicos han de ser ideológicamente neutrales, pero esto no significa la negación de la diversidad religiosa existente en la escuela. Es por este motivo que le corresponde al Estado gestionar el pluralismo religioso e ideológico, no negarlo ni mucho menos, prohibirlo.

No obstante, en la figura del docente en la escuela pública, esta neutralidad significa «una renuncia a cualquier forma de adoctrinamiento ideológico, que es la única actitud compatible con el respeto a la libertad de las familias que, por decisión libre o forzadas por las circunstancias, no han elegido para sus hijos centros docentes con una orientación ideológica determinada y explícita» (STC 5/1981, de 13 de febrero). Por tanto, el no adoctrinamiento a los alumnos es una manifestación de este principio de neutralidad estatal.

Este principio debe interpretarse igualmente en relación con la función de garantía por parte del Estado expresado en el artículo 9.2 CE que afirma corresponder «a los poderes públicos promover las condiciones para que la libertad y la igualdad del individuo y de los grupos en que se integra sean reales y efectivas; remover los obstáculos que impidan o dificulten su plenitud y facilitar la participación de todos los ciudadanos en la vida política, económica, cultural y social». Que en la esfera concreta de la libertad religiosa está conectado con el principio de cooperación del Estado con las confesiones religiosas, reflejado en el artículo 16.3 de la CE al disponer que: «Los poderes públicos tendrán en cuenta las creencias religiosas de la sociedad española y mantendrán las consiguientes relaciones de cooperación con la Iglesia católica y las demás confesiones».

Estas disposiciones constitucionales implican que el Estado en el marco de la neutralidad tendrá en cuenta el factor religioso presente en la sociedad española, manteniendo una actitud no beligerante, sino de cooperación con esta realidad, estableciendo las relaciones de cooperación con las confesiones.

Precisamente, las situaciones y conflictos que se presentan en la escuela pública y que vamos a tratar a continuación tienen una íntima conexión con este principio de neutralidad estatal en materia ideológico-religiosa y la cooperación necesaria con las confesiones religiosas. 


\section{La diversidad religiosa en la escuela: La respuesta jurídica ante determinadas situaciones y conflictos}

En la práctica, el día a día nos muestra que cada vez son más numerosos los conflictos jurídicos en los que el factor religioso está presente, también en la escuela. Una vez establecido el marco jurídico-teórico, hay que observar como se muestra, desarrolla y se gestiona la diversidad religiosa en el ámbito educativo ${ }^{27}$. Dado que la pluralidad religiosa presente en la comunidad educativa, así como que la regulación jurídica no siempre se muestra clara o requiere una interpretación aplicable al supuesto concreto, es precisa una revisión exhaustiva de las normas, la jurisprudencia y observar la gestión en otros ámbitos públicos que puedan dar orientaciones a desarrollar en el ámbito educativo, tomando como elemento clave para solucionar conflictos los principios y derechos establecidos por la comunidad internacional en la Convención sobre los Derechos del Niño de 1989.

Como ejemplos de situaciones y conflictos en los que el factor religioso en la escuela esté presente podemos citar: la presencia de símbolos religiosos bien personales o en el espacio público, la celebración de festividades religiosas por parte de los alumnos y su implicación en la vida escolar, la solicitud de enseñanza religiosa, la petición de adaptaciones del menú en el comedor escolar por motivos religiosos y casos más extremos como los de solicitar dispensa para asistir a determinadas clases o actividades por motivos de conciencia ${ }^{28}$.

En este trabajo nos centraremos en tres supuestos de los anteriormente citados: la simbología religiosa personal de los alumnos y alumnas, la solicitud de adaptación del menú escolar por motivos religiosos y la celebración de las festividades religiosas, cuestiones que en los últimos años han tomado relevancia en el ámbito educativo.

\section{V.1. La simbología religiosa personal de los alumnos y las alumnas}

El Diccionario de la Real Academia de la Lengua define «símbolo» como un «elemento u objeto material que, por convención o asociación, se considera representativo de una entidad, de una idea, de una cierta condición, etc.». El adjetivo «religioso» le confiere la pertenencia a una creencia determinada y el ejercicio del derecho fundamental de libertad religiosa a través de dicho símbolo.

Existen varias clasificaciones de los símbolos religiosos. La clasificación de los símbolos religiosos nos permite distinguir entre símbolos religiosos dinámicos o personales y símbolos religiosos estáticos e institucionales. Los primeros tienen que ver con la vestimenta, la exhibición de atuendos u objetos tales como crucifijos, velos, kipá... Los segundos constituyen elementos que forman parte o se incorporan a un edificio, estructura,

27 VEGA GUTIÉRREZ, A., (Coord.), La gestión de la diversidad religiosa en el sistema educativo español, Thomson Reuters Aranzadi, Navarra, 2014, MORENO ANTÓN, M., «Proyección multicultural de la libertad religiosa en el ámbito escolar», en Revista General de Derecho Canónico y Derecho Eclesiástico del Estado 10 (2006).

28 RODRIGO LARA, B., MESEGUER VELASCO, S., La diversidad religiosa en la escuela: orientaciones jurídicas, Documentos del Observatorio del Pluralismo Religioso en España, 2018. http://www.observatorioreligion.es/publicaciones/documentos_del_observatorio/la_diversidad_religiosa_en_ la_escuela_orientaciones_juridicas/ 
pared..., por ejemplo, la presencia de un crucifijo en el aula de una escuela o en el escudo de una universidad ${ }^{29}$.

Los centros educativos públicos deben responder a las características de pluralidad y neutralidad religiosa como principios rectores de la actividad del Estado a lo que nos hemos referido anteriormente. Por otra parte, deben asumir el objetivo de la educación fijado por el artículo 27.2 CE y las leyes educativas; esto es, «el pleno desarrollo de la personalidad humana en el respeto a los principios democráticos de convivencia y a los derechos y libertades fundamentales».

Conviene advertir que estos supuestos no tienen una solución pacífica por parte de la doctrina jurídica ni por la jurisprudencia, tanto en España como en otros países europeos ${ }^{30}$. Este hecho, unido a la escasa regulación jurídica sobre simbología religiosa, ha causado que sean los propios centros educativos lo que resuelvan en la práctica estas cuestiones a través de los Reglamentos de Régimen Interior (RRI), dotando de diversas soluciones que abarcan desde los más rígidos que prohíben los símbolos de carácter religioso a los más permisivos, que admiten cualquiera de ellos, o simplemente ignoran este tipo de conflictos. El caso más habitual en España es el relativo a la utilización del pañuelo por alumnas musulmanas.

Algunos autores y decisiones de los tribunales de justicia sostienen que habrá que atenerse rigurosamente a lo que se establece en el RRI y al principio de laicidad que debe regir la actuación de las autoridades académicas en los centros educativos públicos, de lo que resulta una escuela pública sin presencia de simbología religiosa de ningún tipo para salvaguardar la neutralidad ideológico-religiosa de los miembros de la comunidad educativa. Sin embargo, otros autores manifiestan que el RRI no puede restringir el ejercicio de los derechos fundamentales más allá de los límites establecidos en los textos internacionales, en la CE y en la LOLR. Por lo que defienden que, en los supuestos en los que el RRI prohíba cubrirse la cabeza, se establezca la excepción por motivos religiosos (p. ej. hiyab) y sanitarios (pañuelos o gorras que cubren la cabeza después de tratamientos médicos) ${ }^{31}$.

En todos los casos, consideramos adecuado mantener la negativa por parte del centro a que se porte el pañuelo en la clase de educación física u otras como prácticas en laboratorios, por motivos de seguridad en el desarrollo de la asignatura. Podría admitirse, no obstante, algunas alternativas al pañuelo, tales como gorros o pañuelos de otro textil más

29 PALOMINO, R., La religión en el espacio público. Los símbolos religiosos ante el Derecho, Digital Reasons, Madrid, 2016.

30 MELÉNDEZ-VALDÉS NAVAS, M., «El uso de símbolos religiosos en la escuela pública en la jurisprudencia del Tribunal Europeo de Derechos Humanos», en Revista Europea de Derechos Fundamentales 17 (2011).

${ }^{31}$ Algunas resoluciones sobre simbología religiosa en la escuela son las del Tribunal Europeo de Derechos Humanos Dogru c. Francia, de 4 de diciembre de 2008, Kervanci c. Francia, de 4 de diciembre de 2008 sobre portar el velo en la clase de educación física, Lautsi c. Italia (Gran Sala), de 18 de marzo de 2011, en la que una madre de dos alumnos solicita la retirada de un crucifijo de la clase de la escuela pública donde asisten sus hijos y como casos resueltos por tribunales españoles, la sentencia del TSJ de Castilla y León de 14 de diciembre de 2009, sobre crucifijo en el aula de un centro público y la sentencia del Tribunal Superior de Justicia de Madrid de 8 de febrero de 2013, que aunque no entra en el fondo del asunto por una cuestión de procedimiento, sí es interesante el voto particular de una de las magistradas en relación al derecho de libertad religiosa de la menor implicada, caso resuelto por sentencia dictada en fecha de 25 de enero de 2012 y el auto de 14 de febrero de 2012, por el Juzgado de lo Contencioso Administrativo ${ }^{\circ} 32$ de Madrid. 
ceñido que impida que se mueva, que pueda engancharse o causar peligro durante el ejercicio de la actividad física o de laboratorio. Esta solución también puede evitar las solicitudes de exención, por objeción de conciencia, a las asignaturas.

Respecto al crucifijo, como símbolo religioso personal, es bastante más común su presencia y prácticamente nula la generación de conflicto sobre ello. Generalmente, se porta en el cuello y suele ser un símbolo pequeño y discreto. Sin embargo, es frecuente observar también su presencia, no tanto como símbolo religioso, sino como un objeto de moda que más que implicar el ejercicio de la libertad religiosa, se desenvuelve en el ámbito del derecho a la propia imagen o de la libertad de expresión.

La cuestión en estos casos, por tanto, se centra no tanto en la dimensión religiosa del símbolo en sí mismo, sino en su adecuación en el desarrollo de la actividad educativa y en la ponderación con los derechos fundamentales de otros alumnos o profesores, cuando tales símbolos religiosos se portan con una intencionalidad proselitista o de adoctrinamiento, por encima de la expresión personal de una determinada creencia religiosa. Son en estos casos cuando se aplican los límites necesarios para el mantenimiento del orden público y la protección del derecho de los demás en el ejercicio de sus derechos fundamentales y libertades públicas.

Como conclusión y a modo de determinar una acción preventiva ante la visión de rechazo inicial a los símbolos religiosos, sería deseable realizar acciones preventivas destinadas a no interpretar el símbolo religioso como un elemento amenazante, sino como una expresión de un derecho fundamental.

\section{V.2. Adaptación de la dieta por prescripciones religiosas en los comedores escolares}

El cumplimiento de los preceptos religiosos relativos a la alimentación es consecuencia directa del ejercicio del derecho de libertad religiosa ${ }^{32}$. Esto se traduce en la vida diaria de aquellos alumnos que son usuarios del comedor escolar, con la consiguiente petición de adaptar el menú escolar a sus prescripciones religiosas.

La prestación del servicio de comedor escolar se configura como un servicio complementario en el ámbito educativo y da respuesta a la realidad social y familiar de sus usuarios que, por razones laborales, por lejanía del centro educativo o por dificultades económicas lo solicitan. Además de este componente asistencial, el comedor escolar se caracteriza por ser un lugar de socialización donde los alumnos, profesores y monitores conviven, siendo un marco adecuado para transmitir hábitos alimentarios saludables y normas de convivencia y respeto.

En España, el marco jurídico básico se establece por la Administración Estatal ${ }^{33}$, aunque dada las competencias autonómicas en materia educativa, habrá que acudir a la normativa propia dictadas como norma general por la Consejería de Educación de cada

32 LIÑÁN GARCíA, A., «El ejercicio de prescripciones o prohibiciones alimentarias conforme a creencias religiosas en el contexto de una relación de sujeción especial en centros públicos en el ordenamiento jurídico español», en Anuario de Derecho Eclesiástico del Estado, vol. 30, 2014, pp. 313-359.

33 Orden de 24 de noviembre de 1992, modificada por la Orden de 30 de septiembre de 1993, y en los Reglamentos Orgánicos de las Escuelas de Educación Infantil y los Colegios de Educación Primaria y de los Institutos de Educación Secundaria de 1996, que establecen las condiciones básicas para la regulación de la organización y funcionamiento del servicio de comedor escolar. 
Comunidad y/o Ciudad Autónoma. En todas ellas, el servicio del comedor se configura como la prestación de un servicio fundamental en la planificación y funcionamiento del centro educativo, que repercute en la calidad del centro, por lo que figura en la programación general anual del colegio y deberá ser aprobado por el Consejo Escolar. La responsabilidad de su programación y su ejecución serán, por tanto, del Consejo Escolar y del equipo directivo del centro.

La planificación de los menús es única para todos los alumnos en general, teniendo en cuenta los criterios generales de alimentación saludable y equilibrada. No obstante, se contemplan excepciones al menú general por motivos médicos debidamente justificados diabetes, alergias alimentarias, etc.-, facilitando menús adaptados a las diversas patologías. Sin embargo, la normativa de comedores escolares no menciona expresamente la excepción por motivos religiosos, por lo que no se regula la obligatoriedad por parte del comedor de ofrecer un menú alternativo de acuerdo con las creencias religiosas del alumnado. A pesar de ello, habrá que atender a la normativa de cada CC.AA., ya que en algunas de ellas (Andalucía, p.ej.) incluye la posibilidad de solicitar un menú alternativo por otras circunstancias debidamente justificadas, entre cuyas causas podríamos considerar justificables los motivos religiosos o de manera expresa en Canarias $^{34}$, Cataluña ${ }^{35}$ y Extremadura ${ }^{36}$.

De hecho, cada vez con más frecuencia, se presentan casos que demandan menús adaptados a las creencias religiosas que, dependiendo de la prescripción, podrán ser más o menos exigentes. La solicitud se referirá a la ausencia en el menú de productos cárnicos solo de algunos animales (generalmente, cerdo) o en su totalidad, así como que se observen unos requisitos en la forma de sacrificio, origen, tratamiento y procesamiento, incluso, en el transporte de los alimentos. Esto último se refiere a la dieta Halal, relativa a la religión islámica, o Kosher para los creyentes judíos, a pesar de que ésta tiene escasa incidencia en la escuela pública, pues las comunidades judías escolarizan por regla general en la escuela privada.

En cuanto a la regulación jurídica de estos supuestos, se debe tener en cuenta la existencia de los acuerdos entre el Estado español y las confesiones ${ }^{37}$. Aunque el acuerdo con las confesiones evangélicas no regula ningún aspecto relativo a la alimentación sí se menciona en el acuerdo con la comunidad judía en referencia a los productos alimentarios

\footnotetext{
34 Orden de 9 de mayo de 2008, por el que se dictan instrucciones para la gestión y funcionamiento de los comedores escolares de los centros públicos escolares para el curso 2008/2009y de planificación para el curso escolar 2009/2010.

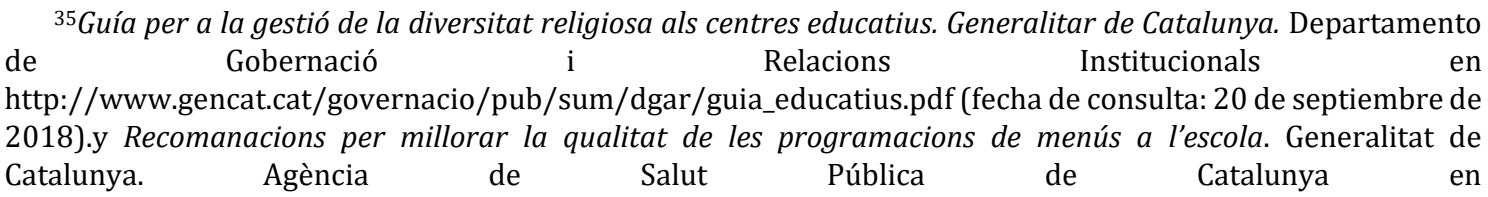
$<$ http://canalsalut.gencat.cat/web/.content/home_canal_salut/professionals/temes_de_salut/salut_alimentari a/documents/arxius/recomana_menus_escola.pdf> (fecha de consulta: 20 de septiembre de 2018).

36 Instrucción 2/2015, del Ente Público Extremeño de Servicios Educativos Complementarios, por la que se regula el funcionamiento del servicio de comedor escolar en centros públicos de Extremadura para el curso $2015 / 2016$.

37 Leyes 24, 25 y 26/1992 de 10 de noviembre de 1992.
} 
en cuanto a la denominación «kosher», «kasher» o «kashrut», mencionando que los sacrificios de animales según los ritos judíos deberán cumplir la normativa vigente, pero no se alude a la colaboración del Estado para facilitar la existencia de menús adaptados en centros públicos (art. 14). El Acuerdo con la Comisión Islámica de España no obliga al Estado a dotar estos menús, únicamente se anima a procurar su existencia (art. 14).

Como medidas o acciones preventivas a tomar en cuenta por los centros educativos en los que se demanden estas dietas por motivos religiosos podemos considerar útil registrar toda petición sobre alimentación en el comedor escolar que atienda a motivos religiosos. Así como mantener comunicación con las familias para conocer las distintas situaciones familiares y considerar la petición como una manifestación del derecho de libertad religiosa y no una opción o preferencia encubierta.

Otro aspecto que podría ayudar a no generar rechazo por parte del resto de la comunidad educativa a los alumnos solicitantes sería realizar actividades entre el alumnado y/o familias que procuren el conocimiento de otras religiones y culturas, en este caso, desde el enfoque de la alimentación.

Por otro lado, y como medidas de la Administración, sería deseable incorporar en el pliego de condiciones de contratación del comedor escolar la posibilidad de ofertar un menú alternativo basado en las creencias religiosas.

Igualmente, se debería atender al número de alumnos solicitantes de una dieta adaptada a sus creencias y valorar la posibilidad de ofertar el menú alternativo o más cantidad de un plato del menú que no contenga carne entre sus ingredientes. En este sentido, la oferta de un menú vegetariano en el comedor escolar podría cubrir las demandas básicas de las comunidades religiosas islámica, judía, evangélica, budistas, sijs e hindúes, como forma de facilitar el ejercicio del derecho fundamental de libertad religiosa, que conviene recordar que se enmarcan en el mismo plano de protección jurídica que los derecho a la vida y a la integridad física y la salud, lo cuales justifican la adaptación de la dieta por motivos médicos (alergias, intolerancias...).

\section{V.3. Festividades y celebraciones religiosas}

La regulación de las festividades laborales de ámbito estatal se fija anualmente por Real Decreto del Ministerio de Trabajo y Seguridad Social y se publica en el Boletín Oficial del Estado. A estos días no laborables hay a que sumar las determinadas por las Comunidades Autónomas y las entidades locales ${ }^{38}$. Por otra parte, el calendario escolar se establece por la Consejería de Educación u órgano competente en la materia de cada Comunidad Autónoma, fijándose por regla general un mínimo de 175 días lectivos para las enseñanzas obligatorias ${ }^{39}$. El calendario escolar lectivo incluye las festividades establecidas

\footnotetext{
38 Competencias a las CCAA y entidades locales con base en el artículo 149.1.7 de la Constitución, competencia expresada en los respectivos estatutos de autonomía. La legislación sobre festividades y descanso laboral regulado en el artículo 37 del Estatuto de los Trabajadores y en los Reales Decretos 2001/1983, de 28 de julio y 1346/1989, de 3 de noviembre.

39 Regulación de las CC AA. basada en la Disposición Adicional quinta de la Ley Orgánica 2/2006, de Educación, de 3 de mayo, modificada por el artículo 92 de la LOMCE.
} 
por el calendario laboral más unos períodos de descanso más amplios por razones pedagógicas.

El calendario laboral fija 14 días festivos. La mayoría de estas fechas tienen carácter religioso (Inmaculada, Viernes Santo, Navidad, etc.) debido a la tradición histórico-religiosa existente en España.

No obstante, en los artículos 12 de las Leyes por las que se aprueban los Acuerdos de 1992 con las confesiones religiosas evangélica, judía y musulmana ${ }^{40}$ se reconoce la posibilidad de celebrar las festividades religiosas que coincidan con el calendario laboral, siempre y cuando sean acordadas con el empresario. En el caso de los alumnos que estudian en colegio público o privado concertado, previa solicitud por parte de los alumnos o de sus padres o de los que ejerzan la patria potestad, se les reconoce tal derecho para ausentarse sin que compute la falta de asistencia.

Una de las situaciones que genera más tensiones es la relativa a la celebración de festividades religiosas en el centro educativo, concretamente las fiestas navideñas, en las que participan los alumnos y profesores en la elaboración de belenes, decoraciones y realización de festivales con temática navideña. Aunque muchas de estas celebraciones han adquirido un carácter más de celebración social que religioso, no puede obviarse el contenido primigenio religioso de la celebración, que es elemento esencial en una gran parte de la población, y lo que da sentido a su celebración. Por este motivo, algunas familias consideran que celebrar estas festividades en la escuela puede derivar en conflictos entre alumnos y con familias que no comparten las mismas creencias religiosas o que, por el contrario, y suele ser lo habitual, no tienen ninguna.

Para resolver estos conflictos deberá tenerse como marco de referencia los principios de neutralidad de la escuela pública y no discriminación, así como ponderar los intereses en juego que faciliten el ejercicio de la libertad religiosa sin vulnerar el derecho de los demás.

Ante una situación como las descritas, algunos centros educativos han determinado suprimir las fiestas o celebraciones en la escuela de contenido religioso. Evidentemente, esta decisión elimina la causa del conflicto de raíz, alegando la neutralidad estatal ante el hecho religioso y el respeto a la libertad religiosa y las conciencias del resto de los alumnos y sus familias. Sin embargo, puede darse la circunstancia que los centros realicen algún tipo de celebración durante estas fechas sustrayendo el contenido religioso, a modo de "fiesta de vacaciones de invierno" o similar.

Como en otras circunstancias descritas en la que interviene el factor religioso, antes de tomar una decisión sobre la celebración de estas festividades y del alcance de las mismas, se requiere analizar las características del centro escolar en cuestión: ubicación, entorno, realidad social de alumnado y sus familias, etc., puesto que ante una postura totalmente contraria a las celebraciones religiosas, bien en su totalidad, bien recurriendo a una celebración "laica", puede igualmente incurrir en vulneración de los derechos de aquellos alumnos y familias que desean dotar de contenido religioso a la Navidad.

${ }^{40}$ Leyes 24, 25 y 26/1992 de 10 de noviembre de 1992. 
Las soluciones que podría preverse al objeto de acomodar el ejercicio de la libertad religiosa al derecho de los demás y al principio de neutralidad de las escuelas públicas podrían resumirse en tres propuestas, si excluimos la más drástica de eliminar cualquier tipo de celebración. La primera sería realizar celebraciones navideñas en el ámbito de la asignatura y el aula de religión. La segunda propuesta, no excluyente con la anterior, sería celebrar la Navidad con presencia de elementos religiosos (belenes, villancicos...), ofreciendo la participación voluntaria del alumnado y del profesorado en aquellas actividades que consideren de acuerdo con su libertad religiosa. Finalmente, una tercera opción es aquella en la que se celebraría o no la Navidad conforme a los deseos de la mayoría de la comunidad educativa, respetando el deseo de la minoría de no participar en ella.

En definitiva, la actuación del centro educativo debe orientarse a conjugar la neutralidad estatal con el principio de cooperación para facilitar a las personas el ejercicio de su libertad religiosa. Esto significa que su posición frente al hecho religioso no es beligerante ni hostil contra la religión. No obstante, los derechos fundamentales, como el de libertad religiosa, son derechos especialmente protegidos, pero no absolutos. Es decir, pueden establecerse límites, aunque serán los estrictamente necesarios para salvaguardar el orden público y los derechos fundamentales de los demás.

Como hemos mencionado anteriormente, los conflictos o rechazo a las manifestaciones religiosas vienen causados en gran parte por el desconocimiento. Es, por tanto, una acción preventiva de estas situaciones, impulsar acciones educativas tendentes a conocer otras culturas y religiones y comunicar las propias con el objetivo de respetarlas por todos.

\section{Conclusiones}

Como nota conclusiva exponemos a continuación algunas ideas clave, fundamentales a la hora de afrontar la diversidad religiosa y los supuestos que den lugar a conflictos de derechos en la escuela.

1. La consideración del menor como sujeto de derechos, capaz de ejercerlos y su grado de influencia en la determinación del propio interés del menor, en especial en relación con el ejercicio de su derecho a la libertad religiosa.

2. Remarcar el papel de los padres como guía de los hijos en función de su edad y madurez, función propia de la institución jurídica de la patria potestad. Esto conlleva que los padres tomen decisiones relativas a derechos fundamentales de los hijos, con base en el interés del menor y en función del deber jurídico establecido por la patria potestad. En este sentido, en relación con los derechos educativos les asiste el derecho a elegir la educación de sus hijos conforme a sus propias convicciones.

3. Para garantizar los derechos fundamentales, los centros educativos públicos, como titulares del servicio que presta el Estado, deben responder a las características de pluralidad y neutralidad religiosa. Igualmente, deben asumir el objetivo de la educación fijado por el artículo 27.2 CE y expresado en la legislación educativa que lo desarrolla, esto es, «el pleno desarrollo de la personalidad humana en el respeto 
a los principios democráticos de convivencia y a los derechos y libertades fundamentales».

4. Los centros educativos deberán garantizar el ejercicio los derechos de libertad religiosa y no discriminación, como derechos fundamentales que son, aplicando de forma restrictiva los límites a estos derechos, tal y como indica la ley.

5. Para evitar la aparición de situaciones conflictivas, se atenderá a la realidad social y personal de la comunidad educativa, ya que nuestra respuesta deberá de orientarse a ella, y no generalizar respuestas que pueden ser válidas en un contexto, pero no en otro diferente. Por lo que esta idease conecta con la anterior en el sentido de que la aplicación de los límites demanda una justa ponderación de los intereses y derechos implicados y su aplicación en un contexto determinado.

6. Se mostrará una actitud de respeto y tolerancia mutua a otras culturas y religiones en el marco de un estado social y de derecho, lo cual favorecerá de un lado, un marco adecuado para ejercer los derechos fundamentales en un clima de distensión y, por otro un acercamiento a conocer diversas culturas y creencias que pueden ser un elemento enriquecedor para la comunidad educativa, evitando que se produzcan los conflictos o que estos se minimicen. 